\title{
KONSTRUKSI AKUNTANSI SOSIAL DAN LINGKUNGAN MELALUI METAFORA SIDIQ, AMANAH, TABLIGH DAN FATONAH
}

\author{
Ronald S. Badu \\ Universitas Negeri Gorontalo \\ ronalbadu@ung.ac.id
}

Received: 25 November 2018; Revised: 1 Desember 2018; Accepted: 5 Desember 2018

\begin{abstract}
Abstrak
Setiap entitas bisnis adalah Amanah Tuhan kepada hambanya, dikarenakan manusia adalah Khalifatullah fil ardh atau 'Abd Allah (hamba Allah) yang seharusnya memahami akan pentingnya sebuah Pertanggungjawaban Sosial dan Lingkungan bukan hanya untuk kelangsungan hidup para pelaku bisnis melainkan juga untuk kelangsungan hidup mahkluk disekitarnya. Oleh karena itu, perlunya memahami aspek manusia yang memiliki andil penting dalam keputusan akuntansi, hingga menyebabkan dalam beberapa dekade terakhir manajemen dan akuntan professional mengidentifikasi kebutuhan tambahan informasi ekonomi yang tidak dapat disampaikan oleh sistem akuntansi atau tidak dilaporkan dalam pelaporan keuangan. Informasi yang dimaksud adalah informasi ekonomi yang tidak selalu bersifat keuangan. Menurut mereka bahwa informasi sesungguhnya akan memberikan makna informasi yang lebih banyak untuk pengambilan keputusan.
\end{abstract}

\section{PENDAHULUAN}

Al-Qur'an bukan hanya sekedar tulisan atau hanya sebuah harta warisan turun temurun, melainkan nilai-nilai dan ajaran yang ada di dalamnya haruslah kita jadikan pedoman untuk diamalkan. Eratnya hubungan agama dengan etika kerja sepatutnya tak bisa dipungkiri lagi bermula dari buku Max Weber "The Protestant Ethic and The Spirit of Capitalism" (1904: 5) menjadi awal keyakinan orang adanya hubungan erat antara ajaran agama dan etika kerja, atau antara penerapan agama dengan pembangunan ekonomi (Rudito dan Famiola, 2007: 56).

Etika sebagai ajaran baik-buruk, benar-salah, atau ajaran tentang moral khususnya dalam perilaku dan tindakan-tindakan ekonomi, bersumber terutama dari ajaran agama. Itulah sebabnya banyak ajaran dan paham dari ekonomi barat menunjuk pada kitab Injil (Bible), dan etika ekonomi Yahudi banyak menunjuk pada Taurat. Demikian etika Islam termuat dalam lebih dari seperlima ayat-ayat yang dimuat dalam Al-Qur'an (Rudito dan Famiola, 2007: 56). Etika yang bersumber dari ajaran agama mengandung prinsip yang berkaitan dengan nilai-nilai kebenaran yang berkaitan dengan sikap dan perilaku yang dikasihi Tuhan (Rudito dan Famiola, 2007: 56; 57). Etika bisnis menurut ajaran Islam ini digali langsung dari Al-Qur'an dan Sunnah Rasul. Dalam ajaran Islam, etika bisnis dalam Islam menekankan pada empat hal, yaitu: Kesatuan (unity), Keseimbangan (equilibrium), Kebebasan (free will) dan Tanggungjawab (responsibility).

Tumbuhnya kesadaran spiritual di dunia korporat dan kehidupan kerja. Mulai diyakini, diperlukan sebagai kekuatan untuk mengatasi efek sistem kapitalisme pada pemikiran bisnis, manajemen dan akuntansi yang merusak lingkungan dan kehidupan manusia. Para eksekutif perusahaan dan kalangan akademis perlu menumbuhkan kesadaran spiritual ini melalui program spiritualisasi perusahaan. Jika motif-motif spiritual ini berhasil "disuntikkan" lewat 


$\begin{array}{ll}\text { Volume } & : 05 \\ \text { Nomor } & : 01 \\ \text { Bulan } & : \text { Januari } \\ \text { Tahun } & : 2019 \\ \text { http } & : \text { //ejurnal.pps.ung.ac.id/index.php/AKSARA/index }\end{array}$

program ini, maka responsivitas perusahaan terhadap tanggungjawab sosial dan lingkungan diharapkan dapat terealisasi.

\section{KAJIAN PUSTAKA}

Pentingnya Akuntansi Sosial dan Lingkungan: Lahirnya paradigma Triple Bottom Line.

Tjahjono (2008) berpendapat bahwa "seperti angin semilir yang kemudian bertiup semakin kencang, begitulah gambaran hembusan wacana Tanggung Jawab Sosial Perusahaan, gaungnya semakin hari, semakin terasa". Dia menambahkan, bahwa tren ini semakin lama akan menjadi tren global. Tidak sedikit perusahaan baik perusahaan kecil, raksasa, lokal, nasional maupun multinasional yang mengklaim bahwa mereka telah merencanakan, menerapkan dan mengimplementasikan CSR dengan baik diperusahaannya. Apalagi ada tekanan dari pihak stakeholders yang mempunyai peranan yang cukup penting. Hal senada diutarakan oleh Freeman (2007) dalam dibawah ini:

"The focus needs to be on how value is created in the basic business proposition. How does this company make customers, suppliers, communities, employees and financiers better off? Capitalism is a system of social cooperation-a system of how we work together to create value for each other. Seeing it any other way can lead to dangerous social policies, and to the tarnishing of the one institution-business-that still has to play a central role in lifting hundreds of millions of people out of proverty in Asia, Africa and Latin America" (Freeman, 2007).

Banyak perusahaan yang telah menggeser paradigma sempit, yang menyatakan bahwa orientasi seluruh kegiatan perusahaan hanyalah profit, di mana aktivitas apapun harus ditakar dari sudut sempit yang akan menambah keuntungan secara langsung atau tidak (Wibisono, 2007). Mengapa? Karena perusahaan itu sebenarnya tidak hanya memiliki sisi tanggung jawab ekonomis saja kepada para shareholders-nya (seperti, bagaimana memperoleh profit dan menaikkan harga saham, atau tanggung jawab legal kepada pemerintah, seperti membayar pajak memenuhi persyaratan AMDAL - Analisa Mengenai Dampak Lingkungan, dan ketentuan lainnya), tetapi jika perusahaan ingin tetap hidup/eksis dan akseptabel, maka harus disertakan pula tanggung jawab yang bersifat sosial, (Tjahjono, 2008).

Tjahjono (2008) menambahkan, bahwa kesadaran tentang pentingnya mempraktekkan CSR ini menjadi tren seiring dengan semakin maraknya kepedulian masyarakat global terhadap produk-produk yang ramah lingkungan. Di samping itu, beberapa peristiwa yang terjadi belakangan ini juga ikut terlibat dalam menyadarkan akan arti penting penerapan CSR/EA. Sebagai contoh yang masih sangat segar yaitu kasus TPST Bojong, di Bogor, Jawa Barat, PT Lapindo Brantas, di Porong, dengan lumpur panasnya. Pada kasus-kasus ini perusahaan dibuat super sibuk karena mengeluarkan anggaran yang tidak kecil bahkan terhenti operasionalnya akibat adanya klaim dari masyarakat.

Dasar pemikirannya, kalau perusahaan hanya semata-mata menggantungkan pada kesehatan keuangan saja, maka tidak akan menjamin perusahaan bisa tumbuh secara berkelanjutan (Sustainable). Agar bisa hidup berkelanjutan maka perusahaan harus memperhatikan dimensi terkait lainnya, yaitu dimensi sosial dan lingkungan. Dari berbagai fakta yang ada telah menunjukkan bahwa bagaimana retensi masyarakat sekitar yang muncul ke permukaan terhadap perusahaan yang di anggap tidak memperhatikan faktor sosial dan lingkungan. Dalam menghadapi tren tersebut, perusahaan mulai melihat serius pengaruh dimensi sosial, dan lingkungan pada setiap aktivitas bisnisnya, karena aspek tersebut bukan suatu pilihan yang terpisah, melainkan berjalan beriringan untuk meningkatkan keberanjuran operasi perusahaan. Disadari bahwa program ini merupakan investasi bagi perusahaan demi pertumbuhan dan keberanjuran perusahaan, yang bukan lagi dilihat sebagai sentra biaya melainkan menjadi sentral laba di masa yang akan datang. Masalah yang berkaitan dengan

48 AKSARA Jurnal Ilmu Pendidikan Nonformal 


$\begin{array}{ll}\text { Volume } & : 05 \\ \text { Nomor } & : 01 \\ \text { Bulan } & : \text { Januari } \\ \text { Tahun } & : 2019 \\ \text { http } & : / / \text { ejurnal.pps.ung.ac.id/index.php/AKSARA/index }\end{array}$

lingkungan merupakan tanggung jawab sosial perusahaan terhadap masyarakat, yang mana ini disebut dengan istilah Corporate Social Responsibilities (CSR). Sulit dipungkiri bahwa wacana CSR yang sebelumnya merupakan isu marjinal kini telah menjelma menjadi isu sentral. CSR kini semakin popular dan bahkan ditempatkan diposisi yang kian terhormat. Karena itu, kian banyak pula kalangan dunia usaha dan pihak-pihak terkait mulai merespons wacana ini (Wibisono, 2007).

Gambar 1- Triple Bottom Line

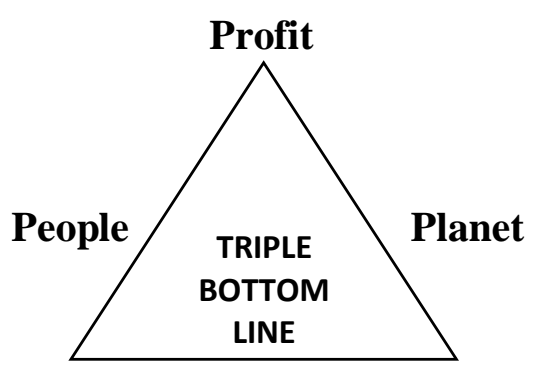

\section{Landasan Teoritis Social Responsibiity dan Environmental Accounting Teori Legitimasi (Legitimacy Theory)}

Legitimasi masyarakat merupakan faktor strategis bagi perusahaan dalam rangka mengembangkan perusahaan kedepan. Hal itu dapat dijadikan sebagai wahana untuk mengonstruksi strategi perusahaan, terutama terkait dengan upaya memposisikan diri di tengah lingkungan masyarakat yang semakin maju.

Menurut Nor Hadi, (2011) legitimasi merupakan keadaan psikologis keberpihakan orang dan kelompok orang yang sangat peka terhadap gejala lingkungan sekitarnya baik fisik maupun non fisik. Menurutnya pula yang dikutip dari O’Donovan (2002) bahwa legitimasi organisasi dapat dilihat sebagai sesuatu yang diberikan masyarakat kepada perusahaan dan seuatu yang diinginkan atau dicari perusahaan dari masyarakat. Dengan demikian, legitimasi merupakan manfaat atau sumber daya potensial bagi perusahaan untuk bertahan.

\section{Teori Stakeholder (Stakeholder Theory)}

Dalam beberapa penjelasan telah disinggung, bahwa perusahaan tidak hanya sekedar bertanggungjawab terhadap para pemilik (shareholder) sebagaimana terjadi selama ini, namun bergeser menjadi lebih luas yaitu sampai pada ranah sosial kemasyarakatan (stakeholder), selanjutnya disebut tanggungjawab sosial (social responsibility). Fenomena itu terjadi, karena adanya tuntutan dari masyarakat akibat negative externalities yan timbul serta ketimpangan sosial yang terjadi (Harahap, 2002). Untuk itu, tanggungjawab perusahaan yang semula hanya diukur sebatas pada indikator ekonomi (economic focused) dalam laporan keuangan, kini harus bergeser dengan memperhitungkan faktor-faktor sosial (social dimentions) terhadap stakeholder, baik internal maupun eksternal (Nor Hadi, 2011: 93).

\section{Teori Kontrak Sosial (Social Contract Theory)}

Kontrak sosial (social contract) muncul adanya interelasi dalam kehidupan sosial masyarakat, agar terjadi keselarasan, keserasian dan keseimbangan, termasuk terhadap lingkungan. Perusahaan, yang merupakan kelompok orang yang memiliki kesamaan tujuan dan berusaha mencapai tujuan secara bersama adalah bagian dari masyarakat dalam lingkungan yang lebih besar (Nor Hadi, 2011: 95). Keberadaannya, sangat ditentukan oleh masyarakat, antara keduanya saling pengaruh-mempengaruhi. Untuk itu, agar terjadi keseimbangan 


$\begin{array}{ll}\text { Volume } & : 05 \\ \text { Nomor } & : 01 \\ \text { Bulan } & : \text { Januari } \\ \text { Tahun } & : 2019 \\ \text { http } & : \text { //ejurnal.pps.ung.ac.id/index.php/AKSARA/index }\end{array}$

(quality), maka perlu kontrak sosial (social contract) baik secara eksplisit maupun implisit sehingga terjadi kesepakatan-kesepakatan yang saling melindungi kepentingannya.

Jika ditelusuri, teori kontrak sosial (social contract) berakar dari karya pemikiran Plato, The Republic (427SM-347SM). Thomas Hobbes (1588-1679) memformalisasikan secara eksplisit konsep Social Contract Theory pada sekitar abad 17 dalam karyanya yang berjudul Leviathan.

\section{METODE PENELITIAN}

Penelitian ini berangkat dari riset sebelumnya yang mengkaji pengaruh budaya dalam akuntansi, beberapa riset terdahulu bahkan pernah menemukan akuntansi yang ada saat ini hanya dipandang bersifat analisa keuangan tanpa memperhatikan aspek lain yang sesungguhnya memiliki pengaruh besar dalam keputusan akuntansi yaitu kualitatif.

Hasil penelitian yang mengkaji tentang realitas masyarakat Gorontalo memberikan petunjuk bahwa akuntansi sangat berperan dalam mewujudkan masyarakat yang sejahtera untuk meraih kebahagiaan sejati. Bagi amaliah (2016) Berbagai definisi akuntansi yang ada saat ini menghadirkan posisi akuntansi yang hanya mengedepankan angka-angka yang bersifat kuantitatif. Cara pandang akuntansi seperti ini berangkat dari prinsip kapitalisme yang memposisikan akuntansi hanya dalam wujud angka-angka. Padahal untuk menggapai kebahagiaan sejati, sesungguhnya realitas kehidupan ini tidak hanya dapat dipandang dari wujud laba yang bersifat kuantitatif semata, namun juga dalam bentuk kualitatif.

Sejalan dengan tujuan riset ini yang ingin mengkonstruksi model Akuntansi Sosial dan Lingkungan dengan mengawinkannya dengan konsep metafora amanah, maka pendekatan yang digunakan dalam riset ini adalah etnometodologi kritis, yang tujuannya memberikan suatu gambaran atau model baru untuk merubah konsep-konsep lama yang sesungguhnya tidak sejalan dengan prinsip berpikir dan bertindak masyarakat. Diperlukan kritik membangun untuk memperbaiki sistem sosial, ekonomi dan budaya agar menjadi lebih baik.

\section{HASIL PENELITIAN DAN PEMBAHASAN}

\section{Akses Menjalin Hubungan dengan Informan: "Susah dahulu, senang kemudian".}

Berkenalan atau menjalin hubungan dengan informan kunci sebenarnya tidak menjadi persoalan, mengingat peneliti dan informan berada dalam satu lintas budaya yang sama. Artinya, hubungan interpersonal informan bukanlah sosok yang harus mendapatkan perlakuan khusus. Misalnya dalam penggunaan bahasa daerah, sehingga adanya hubungan interpersonal yang baik dan cukup kuat dapat memudahkan akses peneliti dalam wawancara dan berinteraksi.

Selanjutnya, dengan asumsi dasar bahwa informan dipandang perlu diistimewakan, sehingga peneliti memulai perkenalan demi perkenalan. Peneliti menggunakan dua cara dalam melakukan perkenalan, yaitu: pertama, melalui kesamaan karakter, sehingga peneliti menggunakan bahasa "yang mudah dipahami" (daerah) dalam berkomunikasi. Dengan menggunakan bahasa "daerah" ini peneliti seperti terbenam dalam wawancara, mengalir begitu saja seperti tidak ada jarak antara peneliti dan informan. Karena menurut peneliti bahasa merupakan jawaban atas setiap persoalan, setumpuk apapun permasalahan yang kita hadapi kalau tidak dimaknai dengan bahasa yang mudah dipahami, maka kitapun akan kesulitan memahaminya. Kedua, peneliti menggunakan legalitas formal atau surat izin meneliti dalam mendapatkan data yang berkaitan dengan penelitian.

Perlunya kedua pendekatan tersebut dengan kekhawatiran bahwa informan memandang saya secara berbeda, terlebih jika penelitian ini secara langsung mengganggu aktivitas informan. Ada tiga informan kunci yang menjadi objek penelitian saya yaitu pak Arto, pak Agus dan pak Samsudin (sebagai nama samaran).

50 AKSARA Jurnal Ilmu Pendidikan Nonformal 


\section{Identifikasi Masalah: “Ancaman lingkungan" sebagai langkah awal penetapan Social Responsibility Accounting (SRA).}

Dalam memahami suatu kebenaran (truth) tentunya kita akan bersentuhan dengan realitas yang ada disekeliling kita, kita tidak akan berani mengatakan si " $A$ " benar dan si " $B$ " itu salah tanpa kita mengetahui betul karakter individu keduanya sebagai bagian masyarakat yang membangun realitas sosial mereka sehingga pentingnya mengetahui karakter manusia (man) dan akuntansi (accounting) sebagai sistem kolektif yang membangun dunianya. Oleh karena itu, penting mengetahui terlebih dahulu bagaimana kebijakan akuntansi lingkungan itu dikonstruksi, adalah perlu untuk mengamati konteks dan proses dimana kebijakan itu lahir. Sebab, konsep kebijakan sendiri memandang aktifitas-aktifitas atau tingkatan-tingkatan masalah merupakan rangkaian logis untuk mencapai puncak kesepakatan. Konstruksi kebijakan merupakan teka-teki kolektif dari suatu kepentingan masyarakat, yang didalamnya terdapat keputusan dan pengetahuan (Hedo, 1974: 305) dalam (Syarifuddin, 2009). Teka-teki ini menurut Hedo adalah bentuk pendefinisian masalah dan penyusunan agenda yang terus berlanjut, seperti "inti” atau "tali" dari seluruh proses kebijakan.

Oleh karena itu dalam mendefinisikan masalah dan bagaimana agenda itu dibentuk, kita harus menelaah lebih kedalam konteksnya, dan tidak terbatas pada hubungan permukaan suatu kekuasaan. Hubungannya dengan itu Syarifuddin, (2009) memberikan arti bahwa perlunya mengamati bagaimana nilai-nilai kepercayaan masyarakat dibentuk oleh kekuatan yang tidak dapat diamati secara kasat mata.

\section{PENUTUP}

Implementasi Akuntansi Sosial dan Lingkungan sesungguhnya merupakan manifestasi bentuk kepedulian perusahaan terhadap lingkungan dan sosial untuk menciptakan dan membangun trust publik terhadap perusahaan. Oleh karena itu, para pelaku bisnis perlunya menumbuh kembangkan kesadaran etika dan tidak mengabaikan nilai-nilai trasendental yang selama ini dianut oleh faham filsafat materialis yang mengukur kebenaran dari sisi realitas fisik semata. Karena akuntansi adalah bagian dari etika dan moral, maka akuntansi perlu mentransformasikan nilai-nilai etika dan moral kedalam lingkup perusahaan. Artinya, dalam kapasitas pertanggungjawaban terhadap lingkungan dan sosial, manajemen dan akuntan menjadikan bisnis sebagai profesi luhur.

Melalui pemahaman informan, studi ini kemudian mengangkat dan mensinergikan nilainilai trasendental (jiwa tauhid) dan bisnis sebagai jalan keluar dari permasalahan sosial dan lingkungan. Dengan mengkonstruk dan memasukkan empat unsur kebenaran sifat-sifat Rasulullah SAW yang patut diteladani yaitu: Siddiq, Amanah, Tabligh dan Fatonah, manifestasi akuntansi sosial dan lingkungan diyakini dapat memproteksi efek sistem kapitalisme, memberikan keberkahan, memberikan pencerahan dan dapat menuntun para pelaku bisnis untuk berlaku adil, jujur, dapat dipercaya dan bijaksana dalam setiap pengambilan keputusan. Studi ini kemudian menemukan bahwa untuk mendapatkan Nilai Perusahaan (Value of Firm) sangat dipengaruhi oleh nilai-nilai trasendental seperti: Siddiq, Amanah, Tabligh dan Fatonah. Artinya, dengan adanya jiwa tauhid tersebut perusahaan bukan hanya tempat untuk mendapatkan keuntungan finansial melainkan dapat pula dijadikan "rumah ibadah" untuk mentransformasikan jiwa tauhid (siddiq, amanah, tabligh dan fatonah) dalam setiap pengambilan keputusan.

Studi ini menemukan bahwa implementasi Akuntansi Sosial dan Lingkungan bukan hanya sekedar konsep, bukan sebatas angka-angka keuangan, bukan selalu mengatasnamakan peraturan perundangan, bukan terjadi karena paksaan dan tuntutan dari masyarakat, bukan 


$\begin{array}{ll}\text { Volume } & : 05 \\ \text { Nomor } & : 01 \\ \text { Bulan } & : \text { Januari } \\ \text { Tahun } & : 2019 \\ \text { http } & : \text { //ejurnal.pps.ung.ac.id/index.php/AKSARA/index }\end{array}$

karena promosi, bukan karena ingin dipandang sebagai sesuatu yang terhormat dan lain-lain sebagainya. Dengan kata lain, bahwa konsep atau bentuk organisasi dan akuntansi sama sekali tidak akan mampu mengarahkan manusia pada kehidupan sejati, kehidupan yang benar, tanpa melibatkan jiwa tauhid.

\section{DAFTAR PUSTAKA}

Burrel, G., dan G. Morgan, 1979. Sociological Paradigms and Organisational Analysis, Heinemann, London.

Chariri. A. 2006. Kritik Sosial atas Pemaknaan Teori dalam Penelitian Pengungkapan Sosial dan Lingkungan, Maksi Undip

Chua, Wai Fong. Oktober 1986. Radical Developments in Accounting Thought. The Accounting Review, Volume LXI, No. 4, Pages 601-632.

Commission of the European Communities. 2006. Implementing the Partnership for Growth and Jobs: Making Europe a Pole of Excellence on Corporate Social Responsibility.

Cooper, C. 1992. "The non and nom of accounting for (m) other nature". Accounting, Auditing \& Accountability Journal, Vol. 5 No. 3, pp. 16-39.

Susilo, Joko. 2008. Green Accounting di Daerah Istimewa Yogyakarta: Studi Kasus antara Kabupaten Sleman dan Kabupaten Bantul. JAAI Vol 12, No. 2 pp. 149-165

Spradley, James P. 1997. Metode Etnografi/James P. Spradley; pener-jemah Misbah Zulfa Elizabeth; Tiara Wacana Yogya, Yogyakarta.

Suadi, Arif, et.al. 1988. Akuntansi Sosial: Implikasi dan Kemungkinan Pengembangan di Indonesia, majalah akuntansi, no. 11 bulan Nopember.

Sugiharto, I. Bambang. 1996. Posmodernisme: Tantangan Bagi Filsafat, Penerbit Kanisius, Yogyakarta.

Syarifuddin. 2009. Keputusan Akuntansi Anggaran: Aksentuasi Drama Politik dan Kekuasaan. Disertasi tidak diterbitkan. Malang: Program Pascasarjana Universitas Brawijaya.

Tilt, Carol A. 2009. Corporate Responsibility, Accounting and Accountants, Flinders University, Australia. pp. 1-23

Tjahjono, Setijo. 2008. Akuntansi Berbasis Lingkungan Sebagai Penyeim-bang Kepentingan Para Stakeholders. Proposal Disertasi tidak dipublikasikan. Disampaikan pada seminar makalah II. Malang: Program Pascasarjana Universitas Brawijaya.

Triyuwono, Iwan. 2009. Akuntansi Syariah; Perspektif, Metodologi dan Teori, Rajawali Pers, Jakarta

Utomo, Muslim. 2000. "Praktik pengungkapan sosial pada laporan tahunan perusahaan di Indonesia", Laporan Penelitian, Simposium Nasional Akuntansi III, IAI Kompertemen Akuntan Pendidik, Jakarta.

Utomo, M. M. 2001. "Wacana Akuntansi Alternatif". Aksamala Institute.

Velazquez, Manuel G. 2005. Etika Bisnis, Konsep dan Kasus - Edisi 5, Andi, Yogyakarta.

Wibisono, Yusuf. 2007. Membedah Konsep dan Aplikasi Corporate Social Responsibilities. FASCO Bandung.

Wiedmann, T. and Manfred, L. 2006. "Third Annual International Sustainable Development Conference Sustainability - Creating the Culture”. 15-16 November 2006, Perth, Scotland

Wood, D. 1991. "Corporate Social Performance Revisited". Academy of Management Review, Vol.4, pp. 691-718.

Zohar, Danah dan Ian Marshall. 2005. Spiritual Capital, Memberdayakan SQ di Dunia Bisnis. Mizan: Bandung

Zohar, Danah dan Ian Marshall. 2007. SQ: Kecerdasan Spiritual. Mizan: Bandung.

52 AKSARA Jurnal Ilmu Pendidikan Nonformal 